\title{
Catfish Plotosus lineatus are prey for the rare seasnake Hydrophis major in New Caledonia
}
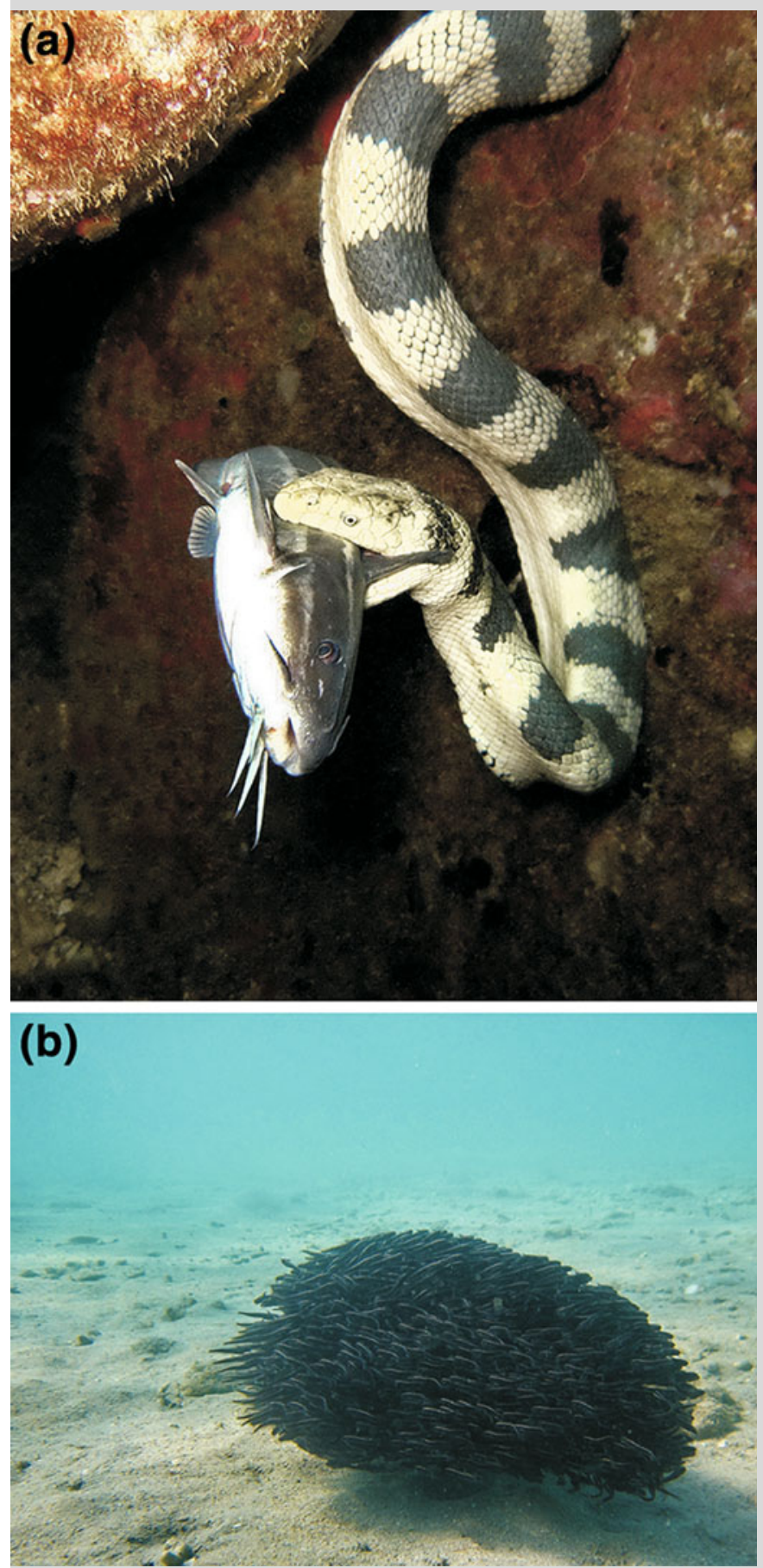

Fig. 1 a Adult $H$. major $(1.5 \mathrm{~m})$ catching a $25-30-\mathrm{cm}$ TL $P$. lineatus,

SW lagoon of New Caledonia. b Typical aspect of a large school of small $P$. lineatus targeted by $H$. major during observation. Credits/photographs: Jack Berthomier, with permission
Seasnakes are potential major predators in coral reef ecosystems (Ineich et al. 2007) but remain poorly studied. In New Caledonia, 14 species of seasnakes are reported but only Laticauda laticaudata and the endemic L. saintgironsi, widely distributed around the island, are abundant on most reefs and islets within the lagoon (Brischoux et al. 2011). Other seasnakes remain largely unstudied, and there are no reliable observations of most species.

Hydrophis major is distributed from New Caledonia to South Papua New Guinea and northeast Australia. Observations were made from July 2010 to July 2011, totalizing about $600 \mathrm{~h}$ of snorkeling $(\mathrm{N} \approx 110$ dives) at depths of 0-25 $\mathrm{m}$ in the SW lagoon of New Caledonia. In total, only $9 \mathrm{H}$. major were seen, that is, 0.015 individual. $\mathrm{h}^{-1}$, always between depths of 0 and $5 \mathrm{~m}$ (Jack Berthomier, personal communication). The surface area explored can be approximately estimated at $500 \mathrm{~m}^{2} \cdot \mathrm{h}^{-1}$, resulting in a mean density of $H$. major of 0.3 individual.ha ${ }^{-1}$. Thus, each observation of this seasnake is a rare event and must be recorded.

Among the 9 seasnakes seen, predation on fish was observed 4 times and always involved Plotosus lineatus. One attack, by a seasnake of about $1.5 \mathrm{~m}$, occurred at dusk and targeted a fish of $25-30 \mathrm{~cm}$ TL belonging to a small group of fish $(<10$ individuals $)$ hiding in a reef cave (Fig. 1a). The other three successful attacks (seasnakes of about $1.0-1.2 \mathrm{~m}$ ) occurred in the afternoon and focused on several small fish individuals ( $5 \mathrm{~cm}$ TL) belonging to large schools (Fig. 1b). The diet of H. major is poorly known, but the rare existing literature reports $P$. lineatus as possible prey (Voris and Voris 1983). Our observations, thus, clearly reinforce this view and also highlight that fish venom and spines like those found on Plotosus spp. are not effective defense against predators such as seasnakes.

\section{References}

Brischoux F, Bonnet X, Cherel Y, Shine R (2011) Isotopic signatures, foraging habitats and trophic relationships between fish and seasnakes on the coral reefs of New Caledonia. Coral Reefs 30:155-165

Ineich I, Bonnet X, Brischoux F, Kulbicki M, Séret B, Shine R (2007) Anguilliform fishes and seakraits: neglected predators in coral-reef ecosystems. Mar Biol 151:793-802

Voris HK, Voris HH (1983) Feeding strategies in marine snakes: an analysis of evolutionary, morphological, behavioral and ecological relationships. Am Zool 23:411-425

Y. Letourneur $(\bowtie) \cdot$ M. J. Briand

Laboratoire LIVE, Labex «Corail», Université de la NouvelleCalédonie, BP R4, 98851 Nouméa cedex, New Caledonia e-mail: yves.letourneur@univ-nc.nc

M. J. Briand

UPR CNRS 1934, Centre d'Études Biologiques de Chizé, 79360 Beauvoir-sur-Niort, France 